\title{
Glutathione Is Involved in the Granular Storage of Dopamine in Rat PC12 Pheochromocytoma Cells: Implications for the Pathogenesis of Parkinson's Disease
}

\author{
Benjamin Drukarch, Cornelis A. M. Jongenelen, Erik Schepens, Cornelis H. Langeveld, and \\ Johannes C. Stoof \\ Department of Neurology, Graduate School Neurosciences Amsterdam, Research Institute Neurosciences Vrije \\ Universiteit, 1081 BT Amsterdam, The Netherlands
}

Parkinson's disease (PD) is characterized by degeneration of dopamine (DA)-containing nigro-striatal neurons. Loss of the antioxidant glutathione (GSH) has been implicated in the pathogenesis of PD. Previously, we showed that the oxidant hydrogen peroxide inhibits vesicular uptake of DA in nigro-striatal neurons. Hydrogen peroxide is scavenged by GSH and, therefore, we investigated a possible link between the process of vesicular storage of DA and GSH metabolism. For this purpose, we used rat pheochromocytoma-derived PC12 cells, a model system applied extensively for studying monoamine storage mechanisms. We show that depletion of endogenous DA stores with reserpine was accompanied in PC12 cells by a longlasting, significant increase in GSH content the extent of which appeared to be inversely related to the rate of GSH synthesis. A similar increase in GSH content was observed after depletion

Parkinson's disease (PD) is characterized primarily by a loss of dopamine (DA) in the striatum caused by degeneration of DAergic neurons in the zona compacta of the substantia nigra (SN) (Gibb and Lees, 1991). Although the cause of PD is still unknown, oxidative stress has been implicated as a pathogenetic factor. According to this so called "free radical hypothesis," the degeneration of the nigro-striatal system in PD is related to the relatively high exposure of these neurons to reactive oxygen species (ROS), in particular hydrogen peroxide $\left(\mathrm{H}_{2} \mathrm{O}_{2}\right)$, produced during both the enzymatic (monoamine oxidase-catalyzed) and nonenzymatic (auto-oxidative) breakdown of DA (Adams and Odunze, 1991; Olanow, 1992). Thus, DAergic cell death in PD may be caused by an overproduction of ROS and/or a diminished protection against them. Evidence to support the "free radical hypothesis" has come from postmortem investigations of PD brains, which consistently show an increase in the indices of oxidative stress in the SN at the time of death (Hirsch et al., 1991; Jenner, 1993). One of these indices, possibly even preceding the loss of DA (Dexter et al., 1994), is a decrease in the level of glutathione (GSH) in the Parkinsonian SN (Riederer et al., 1989; Sofic et al., 1992; Jenner, 1993). GSH, the most abundant free thiol in mammalian cells (Meister and Andersson, 1983), is considered to be a

Received March 19, 1996; revised July 12, 1996; accepted July 18, 1996.

We thank Dr. Robbert J. Slingerland (University of Amsterdam) for providing us with the PC12 cell line.

Correspondence should be addressed to Dr. Benjamin Drukarch, Research Institute Neurosciences Vrije Universiteit, Department of Neurology, Boechorststraat 7, 1081 BT Amsterdam, The Netherlands.

Copyright (C) 1996 Society for Neuroscience $0270-6474 / 96 / 166038-08 \$ 05.00 / 0$ of DA stores with the tyrosine hydroxylase inhibitor $\alpha$-methyl$p$-tyrosine. In the presence of $\alpha$-methyl-p-tyrosine, refilling of the DA stores by exogenous DA reduced GSH content back to control level. Lowering of PC12 GSH content, via blockade of its synthesis with buthionine sulfoximine, however, led to a significantly decreased accumulation of exogenous $\left[{ }^{3} \mathrm{H}\right] \mathrm{DA}$ without affecting uptake of the acetylcholine precursor $\left[{ }^{14} \mathrm{C}\right]$ choline. These data suggest that GSH is involved in the granular storage of DA in PC12 cells and that, considering the molecular characteristics of the granular transport system, it is likely that GSH is used to protect susceptible parts of this system against (possibly DA-induced) oxidative damage.

Key words: Parkinson's disease; oxidative stress; glutathione; dopamine; PC12 cells; neurotransmitter uptake; vesicular storage

major antioxidant in the brain. Thus, GSH has been shown to detoxify (organic and inorganic) hydroperoxides including the $\mathrm{H}_{2} \mathrm{O}_{2}$ formed during the oxidative metabolism of DA (Spina and Cohen, 1988, 1989).

To prevent breakdown of DA before its release from presynaptic endings, the transmitter is taken up and stored in presynaptic granules. This process is effected through the action of a transporter protein (Johnson, 1988). Interference with granular storage, for instance via blockade of the ligand-binding site on the transporter, leads to an enhanced turnover of DA, inducing considerable oxidative stress as a consequence of $\mathrm{H}_{2} \mathrm{O}_{2}$ production (Spina and Cohen, 1989). Recently, we have shown that, apart from generating oxidative stress, $\mathrm{H}_{2} \mathrm{O}_{2}$ is able to inhibit storage of $\mathrm{DA}$ in the nigro-striatal system through an as yet undefined interaction with the granular uptake mechanism (Langeveld et al., 1995). Interestingly, the DA storage system appeared to be substantially more sensitive to $\mathrm{H}_{2} \mathrm{O}_{2}$ compared with that of other transmitters, such as noradrenaline (NA) and acetylcholine (ACh) (Langeveld et al., 1995). Based on these data, we proposed that the degeneration of the nigro-striatal system in PD may be the outcome of a self-sustaining cycle that is initiated by lowering of the capacity to scavenge the $\mathrm{H}_{2} \mathrm{O}_{2}$ released during normal DA metabolism, leading to a decrease in the granular storage and enhanced breakdown of DA, inducing more oxidative stress, disturbance of neuronal function and, eventually, cell death. Considering our observation that $\mathrm{H}_{2} \mathrm{O}_{2}$ preferentially interferes with presynaptic storage of DA and the fact that, in the mammalian brain, $\mathrm{H}_{2} \mathrm{O}_{2}$ is detoxified mainly by GSH (Maker et al., 1981; DiMonte et al., 1992), whose levels are decreased in PD, we 
initiated a series of in vitro experiments to investigate a possible linkage between granular uptake of DA and GSH metabolism. For this purpose, we used a rat pheochromocytoma-derived PC12 cell line (Greene and Tischler, 1976) which, in contrast to tissue slices or primary neuronal cultures, consists of a homogeneous population of DA containing cells that have been demonstrated to synthesize, store, and release DA in a similar manner as neurons (Greene and Rein, 1977). Moreover, these cells are known to contain both GSH and the enzyme systems involved in its metabolism (Pan and Perez-Polo, 1993; Sampath et al., 1994).

\section{MATERIALS AND METHODS}

Materials. Radiolabeled DA and choline were obtained from Amersham International (Little Chalfont, UK). DL- $\alpha$-methyl- $p$-tyrosine ( $\alpha \mathrm{MPT})$ was from Research Biochemicals (Natick, MA), and reserpine was from De Onderlinge Pharmaceutische Groothandel (Utrecht, The Netherlands). Tissue culture media and supplements were obtained from Gibco Netherlands BV (Breda, The Netherlands), whereas all other chemicals and drugs, unless noted otherwise, were obtained from Sigma (St. Louis, MO).

Cell culture. PC12 cells, originally described by Greene and Tischler (1976), were grown in $80 \mathrm{~cm}^{2}$ tissue culture flasks containing DMEM/ Ham's F-10 (1:1) supplemented with $15 \%$ fetal calf serum (FCS), 2 mM L-glutamine, penicillin $(100 \mathrm{U} / \mathrm{ml})$, and streptomycin $(50 \mu \mathrm{g} / \mathrm{ml})$ at $37^{\circ} \mathrm{C}$ under an atmosphere of $5 \% \mathrm{CO}_{2} / 95 \%$ air. After 1 week, in which the culture medium had been changed once or twice, the medium was removed and the cells were trypsinized according to Van Muiswinkel et al. (1995). After trypsinization, viable cells in the resulting cell suspension were counted by trypan blue exclusion in a hemocytometer. Subsequently, cells were plated in 12 -well culture dishes, containing $1 \mathrm{ml}$ of culture medium in each well, at a density of $2.5 \times 10^{5}$ cells/well for all experiments. Before culturing, both culture flasks and dishes had been precoated with poly-L-lysine $(100 \mu \mathrm{g} / \mathrm{ml})$. Investigations were started when the cells had been in the culture dishes for at least $24 \mathrm{hr}$ and the cultures were maintained, without a change of medium, for a maximum of $4 \mathrm{~d}$ depending on the type of experiment (see Results).

GSH assay: sample preparation. Samples were prepared for the measurement of cellular total GSH content, that is, reduced GSH + oxidized glutathione (GSSG), according to the method described by Redegeld et al. (1988), with the exception that 5-sulfosalicylic acid (SSA) was used instead of perchloric acid to extract GSH. Preparation of the samples was performed at $4^{\circ} \mathrm{C}$. Cells were rinsed free of culture medium or phosphate buffer (see below) before $250 \mu \mathrm{l}$ of $2.5 \%$ (w/v) SSA was added. Subsequently, culture dishes were quickly frozen $\left(-70^{\circ} \mathrm{C}\right)$ and thawed to ensure cell lysis. The lysate was centrifuged to remove denaturated protein. From the supernatant a volume of $100 \mu \mathrm{l}$ was taken to which $10 \mu \mathrm{l}$ of $\mathrm{H}_{2} \mathrm{O}$ and, after $5 \mathrm{~min}, 20 \mu \mathrm{l}$ of $\mathrm{K}_{3} \mathrm{PO}_{4}(3 \mathrm{M}, \mathrm{pH} 13.5)$ were added for incubation at room temperature. After a $10 \mathrm{~min}$ period, the samples were then neutralized with $50 \mu \mathrm{l}$ of a $10 \%(\mathrm{w} / \mathrm{v})$ SSA solution. In a subset of samples, instead of $\mathrm{H}_{2} \mathrm{O}, 10 \mu \mathrm{l}$ of $11 \mathrm{mM} N$-ethyl-maleimide (NEM) was added to determine GSSG content. In these samples, alkaline hydrolysis by $\mathrm{K}_{3} \mathrm{PO}_{4}$ was used for inactivation of excess NEM.

GSH assay: enzyme recycling procedure. GSH was determined spectrophotometrically according to Tietze (1969) with adaptations by Baker et al. (1990). The procedure was performed at room temperature. In short, $50 \mu \mathrm{l}$ of GSH or GSSG standards, samples, or blanks was pipetted into the wells of a microtiter plate. A buffer of $100 \mathrm{~mm}$ sodium phosphate and $1 \mathrm{~mm}$ EDTA (Fluka Chemie, Buchs, Switzerland; pH 7.5) was used to prepare a reaction mixture consisting of $0.225 \mathrm{~mm} 5,5^{\prime}$-dithio-bis(2-nitrobenzoic acid) (DTNB), $0.3 \mathrm{~mm}$ NADPH (tetrasodium salt, Boehringer Mannheim, Mannheim, Germany), and $2.8 \mathrm{U} / \mathrm{ml}$ GSSG reductase. Subsequently, $100 \mu \mathrm{l}$ of freshly prepared reaction mixture was added to each of the wells. The absorbance at $405 \mathrm{~nm}$ (TitertekPlus Microplate Reader, ICN Biomedicals, Amsterdam, The Netherlands) was measured immediately after the addition of the reaction mixture and at intervals of $1 \mathrm{~min}$ thereafter during $6 \mathrm{~min}$. Total GSH and GSSG content was calculated from the rate of increase in absorbance.

Cellular catecholamine content. Cells were rinsed free from culture medium or phosphate buffer (see below) and subsequently lysed by adding $400 \mu \mathrm{l}$ of ice-cold perchloric acid $(0.2 \mathrm{~N})$. After this procedure, the culture dishes were frozen and thawed and the lysate then centrifuged as described above. Aliquots of the supernatants were stored at $-20^{\circ} \mathrm{C}$ before the analysis of catecholamine content by HPLC with electrochemical detection. HPLC analysis was performed essentially as described previously (Westerink and Mulder, 1981; Van Muiswinkel et al., 1995), using a Guardcolumn (Phase Sep, Deeside, UK) in combination with a reverse-phase column filled with Spherisorb (3 $\mu \mathrm{m}$, SRODS2; Phase Sep) and an amperometric electrochemical detector (Antec, Leiden, The Netherlands). The mobile phase consisted of $0.05 \mathrm{M}$ citric acid, $0.05 \mathrm{M}$ phosphoric acid, $1.5 \mathrm{~mm}$ octanesulfonic acid (sodium salt monohydrate, Janssen Chimica, Beerse, Belgium), $0.2 \mathrm{~mm}$ EDTA, and $5 \%$ (v/v) methanol, $\mathrm{pH} 2.5$. The detector potential was set at $+750 \mathrm{mV}$ versus a $\mathrm{K} / \mathrm{KCl}$ reference electrode. Catecholamine content was calculated against standards that had been subjected to the same treatment as the samples.

Cell survival assay. To determine cell survival, we used the 3-(4,5dimethylthiazol-2-yl)-2,5-diphenyltetrazolium bromide (MTT) assay as described previously (Langeveld et al., 1992) with some adaptations. An MTT stock solution was prepared and stored at $-20^{\circ} \mathrm{C}$. On the day of the assay, $100 \mu \mathrm{l}$ of MTT solution $(5 \mathrm{mg} / \mathrm{ml})$ was added to each well of the culture dishes containing $1 \mathrm{ml}$ of culture medium. Subsequently, incubation of the cultures took place for $2 \mathrm{hr}$ at $37^{\circ} \mathrm{C}$ under an atmosphere of $5 \% \mathrm{CO}_{2} / 95 \%$ air. Thereafter, the medium was removed and replaced by $2 \mathrm{ml}$ of dimethylsulfoxide (DMSO) to which $0.5 \%(\mathrm{v} / \mathrm{v})$ FCS had been added. After formazan solubilization by vibration on a plate shaker, a 150 $\mu l$ sample was drawn from this solution and pipetted into a microtiter plate. The absorbance of each well was measured at $540 \mathrm{~nm}$ using the TitertekPlus microplate reader described above. Absorbance data were calculated by subtracting the mean of "background" readings obtained from identical incubations in the absence of cells.

Radioligand uptake. Cells were rinsed free of culture medium and

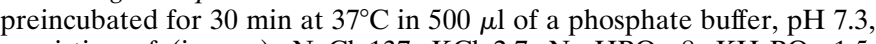
consisting of (in mM): $\mathrm{NaCl} 137, \mathrm{KCl} 2.7, \mathrm{Na}_{2} \mathrm{HPO}_{4} 8, \mathrm{KH}_{2} \mathrm{PO}_{4} 1.5$, $\mathrm{MgCl}_{2} 0.5, \mathrm{CaCl}_{2} 1.2$, and $\mathrm{D}-(+)$-glucose 5 . To this buffer $0.5 \%(\mathrm{w} / \mathrm{v})$ bovine serum albumin (BSA) had been added. Subsequently, the cultures were washed and incubated for $20 \mathrm{~min}$ with BSA containing buffer to which $\left[{ }^{3} \mathrm{H}\right] \mathrm{DA}$ (specific activity $45 \mathrm{Ci} / \mathrm{mmol}$; final concentration $65 \mathrm{~nm}$ ) and/or $\left[{ }^{14} \mathrm{C}\right]$ choline (specific activity $55 \mathrm{mCi} / \mathrm{mmol}$; final concentration 8.5 $\mu \mathrm{M})$ had been added. Thereafter, cultures were washed seven times with buffer before the accumulated radioactivity was extracted by a $30 \mathrm{~min}$ incubation with acidified ethanol (95\% ethanol/5\% $0.1 \mathrm{~N} \mathrm{HCl})$ and quantified by liquid scintillation counting (Packard TriCarb 1900 AC liquid scintillation analyzer, Groningen, The Netherlands). If uptake inhibitors were used, they were added to the buffer at the start of the preincubation period and remained present throughout the experiment.

Protein content. Protein content was determined, according to the method of Bradford (1976) and using BSA as a standard, in parallel cultures to those used for the above described measurements.

Statistical analysis. Statistical analysis was performed using a two-tailed Student's $t$ test.

\section{RESULTS}

\section{Effect of reserpine on GSH content}

Under our culture conditions, $\sim 95 \%$ of the total catecholamine content of the PC12 cells consisted of DA (data not shown). As expected, incubation of the cells for either 1 or $3 \mathrm{hr}$ in a phosphate buffer (see Materials and Methods) to which the granular uptake inhibitor reserpine (50 nM; Carlsson, 1965) had been added led to a time-dependent decrease of DA content (Fig. 1A). However, whereas incubation of the $\mathrm{PC} 12$ cells in the buffer timedependently lowered total GSH levels, this phenomenon was not observed when reserpine was present (Fig. 1B). The decrease in GSH content under control condition during incubation with buffer was prevented by addition of cystine $(10-100 \mu \mathrm{M})$ which, after uptake, is reduced inside the cell into the GSH precursor cysteine. In fact, a $3 \mathrm{hr}$ incubation with cystine induced a concentration-dependent increase in GSH levels which, between experiments, averaged from $0.7-2.0 \mathrm{nmol} / \mathrm{mg}$ protein in the absence of cystine to $8.7-18.3 \mathrm{nmol} / \mathrm{mg}$ protein in the presence of $100 \mu \mathrm{M}$ cystine (see legend to Fig. 2). In the presence of cystine, a statistically significant elevation of GSH content was noted after addition of reserpine ( $50 \mathrm{~nm}$, Fig. 2), without alteration of its DA content decreasing action (data not shown). Interestingly, this effect of reserpine appeared to be inversely related to the concentration of cystine in the buffer and thus, possibly, to cellular 
A

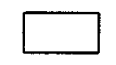
time control

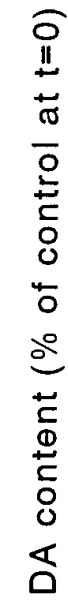

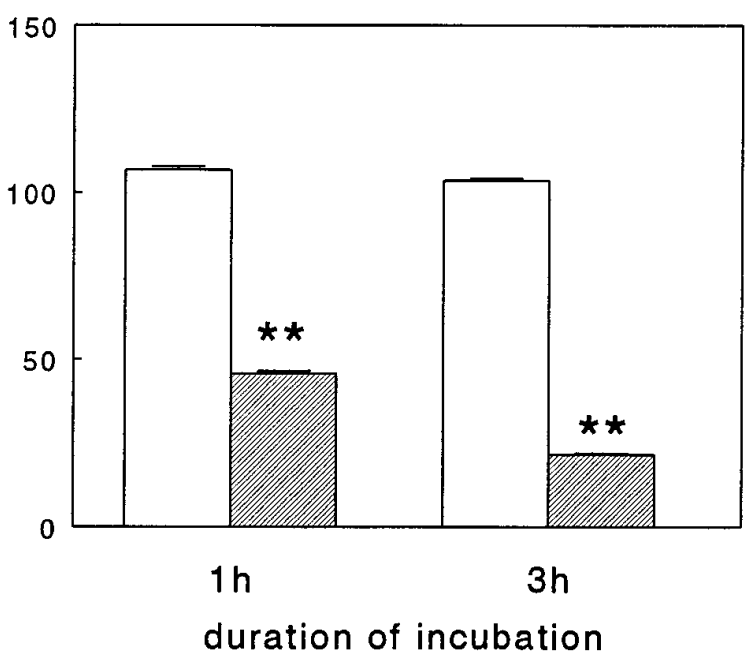

reserpine

duration of incubation
B

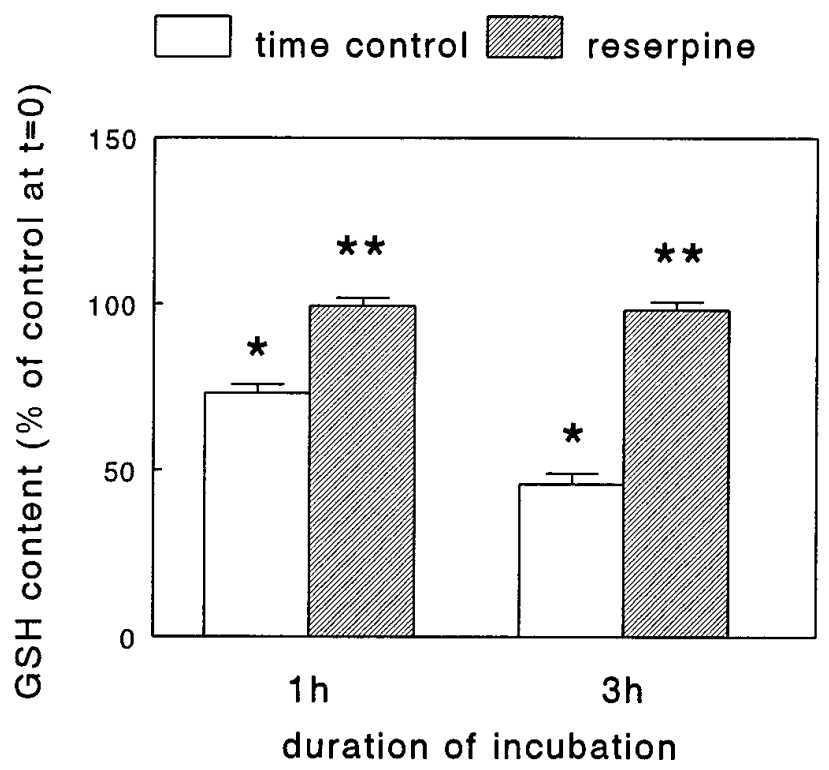

Figure 1. Effect of reserpine on dopamine $(D A)$ content $(A)$ and glutathione $(G S H)$ content $(B)$ of PC12 cells. PC12 cells, cultured for 2 d, were rinsed free of culture medium and incubated for either 1 or $3 \mathrm{hr}$ at $37^{\circ} \mathrm{C}$ in a phosphate buffer (see Materials and Methods) in the absence or presence of 50 nM reserpine, respectively. Subsequently, the cells were lysed and the DA, GSH, and protein content in parallel cultures was determined as detailed in Materials and Methods. Data represent the mean \pm SEM $(n=5-6)$ from two independent experiments. Between experiments, at the start of incubation (i.e., $t=0$ ), DA content averaged from 1.8 to $3.3 \mathrm{nmol} / \mathrm{mg}$ protein, whereas GSH content averaged from 1.6 to $3.1 \mathrm{nmol} / \mathrm{mg}$ protein. Therefore, the data are expressed as percentage of DA or GSH content at $t=0 .{ }^{*} p<0.001$ versus control at $t=0$; ${ }^{*} p<0.001$ versus respective time control.

GSH levels. In contrast to cystine, incubation of cells for $3 \mathrm{hr}$ with buffer containing $100 \mu \mathrm{M}$ L-buthionine-S, $R$-sulfoximine (BSO), an inhibitor of GSH synthesis (Meister, 1991), led to a decrease of GSH content below control values (see legend to Table 1). However, the presence of BSO did not prevent the reserpine (50 $\mathrm{nM}$ )-mediated effect on GSH levels from occurring (Table 1). In all of the above described experiments, the GSSG levels remained below the limit of detection $(0.05 \mathrm{nmol} /$ well $)$. Thus, we concluded that most of the GSH present in the cells was in the reduced form and decided to refrain from any further attempts at measurement of GSSG in the follow-up experiments. Furthermore, in this set of

Table 1. Effect of BSO on the reserpine-induced increase in glutathione content in PC12 cells

\begin{tabular}{ll} 
Treatment & $\begin{array}{l}\text { Glutathione content } \\
\text { (\% respective control) }\end{array}$ \\
\hline No drug & $100 \pm 3.4$ \\
Reserpine $(50 \mathrm{nM})$ & $222 \pm 14.5^{*}$ \\
BSO $(100 \mu \mathrm{M})$ & $100 \pm 7.6$ \\
BSO $(100 \mu \mathrm{M})+$ reserpine $(50 \mathrm{nM})$ & $276 \pm 9.2^{*}$
\end{tabular}

After $2 \mathrm{~d}$ of culture, PC12 cells were rinsed free of medium and incubated for $3 \mathrm{hr}$ at $37^{\circ} \mathrm{C}$ in a phosphate buffer (see Materials and Methods) in the absence of drugs or in the presence of reserpine alone, BSO alone, or the combination of BSO and reserpine, respectively. Data represent the mean $\pm \operatorname{SEM}(n=5-6)$ from two independent experiments and are expressed, in case of reserpine alone, as percentage of glutathione content after $3 \mathrm{hr}$ in the absence of drugs and, in case of the combination of BSO and reserpine, as percentage of glutathione content after $3 \mathrm{hr}$ in the presence of BSO alone. In the absence of drugs, the glutatione content after a $3 \mathrm{hr}$ incubation amounted to $45.8 \pm 3.2 \%$ from control at $t=0 \mathrm{hr}$, whereas in the presence of BSO glutathione content after a $3 \mathrm{hr}$ incubation amounted to $26.7 \pm$ $2.4 \%$ from control (mean \pm SEM; $p<0.001$ vs incubation in absence of drugs). ${ }^{*} p<0.001$ vs respective control. experiments no extracellular GSH was detected in the incubation buffer under either control or treatment conditions.

Treatment of PC12 cells with reserpine (50 nM) added to the culture medium for up to $3 \mathrm{~d}$ induced a decrease of cellular DA content down to $\sim 1.5 \%$ of (time)control values (Table 2 ). The maximum level of DA depletion was already attained after a $24 \mathrm{hr}$ incubation period and remained stable throughout the experiment. At the same time, in the presence of reserpine, the levels of

Table 2. Effect of treatment of PC12 cells for up to $3 \mathrm{~d}$ with reserpine on the GSH, DA, and DOPAC content

Content (\% respective control)

\begin{tabular}{llcc}
\cline { 2 - 4 } Treatment & GSH & DA & DOPAC \\
\hline $24 \mathrm{hr}$ no drug & $100 \pm 12.3$ & $100 \pm 0.3$ & $100 \pm 0.8$ \\
$24 \mathrm{hr}$ reserpine (50 nM) & $424 \pm 2.8^{a}$ & $1.3 \pm 0.05^{a}$ & $92.8 \pm 1.1^{b}$ \\
$48 \mathrm{hr}$ no drug & $100 \pm 13.8$ & $100 \pm 1.5$ & $100 \pm 5.3$ \\
$48 \mathrm{hr}$ reserpine (50 nM) & $296 \pm 5.5^{a}$ & $1.4 \pm 0.05^{a}$ & $85.4 \pm 1.0$ \\
$72 \mathrm{hr}$ no drug & $100 \pm 8.3$ & $100 \pm 0.9$ & $100 \pm 1.5$ \\
$72 \mathrm{hr}$ reserpine (50 nM) & $414 \pm 1.7^{a}$ & $1.4 \pm 0.02^{a}$ & $88.0 \pm 1.2^{c}$
\end{tabular}

After an initial $24 \mathrm{hr}$ drug-free culture period, without a change of medium (see Materials and Methods), PC12 cells were kept in culture for an additional 24, 48, or $72 \mathrm{hr}$ period in the absence (no drug) or presence of $50 \mathrm{~nm}$ reserpine, respectively. At the end of each incubation period, samples were prepared for determination of GSH, DA, and DOPAC content in parallel cultures, respectively, as detailed in Materials and Methods. Subsequent to preparation, all samples were stored at $-20^{\circ} \mathrm{C}$ to ensure that determination of GSH, DA, and DOPAC content would take place on the same day. Data represent the mean \pm SEM of a typical experiment performed in triplicate and are expressed as percentage of respective control (i.e., the value obtained for the respective incubation period in the absence of drug).

${ }^{a} p<0.001$ vs respective control.

${ }^{b} p<0.01$ vs respective control.

${ }^{c} p<0.005$ vs respective control. 


\section{control reserpine}

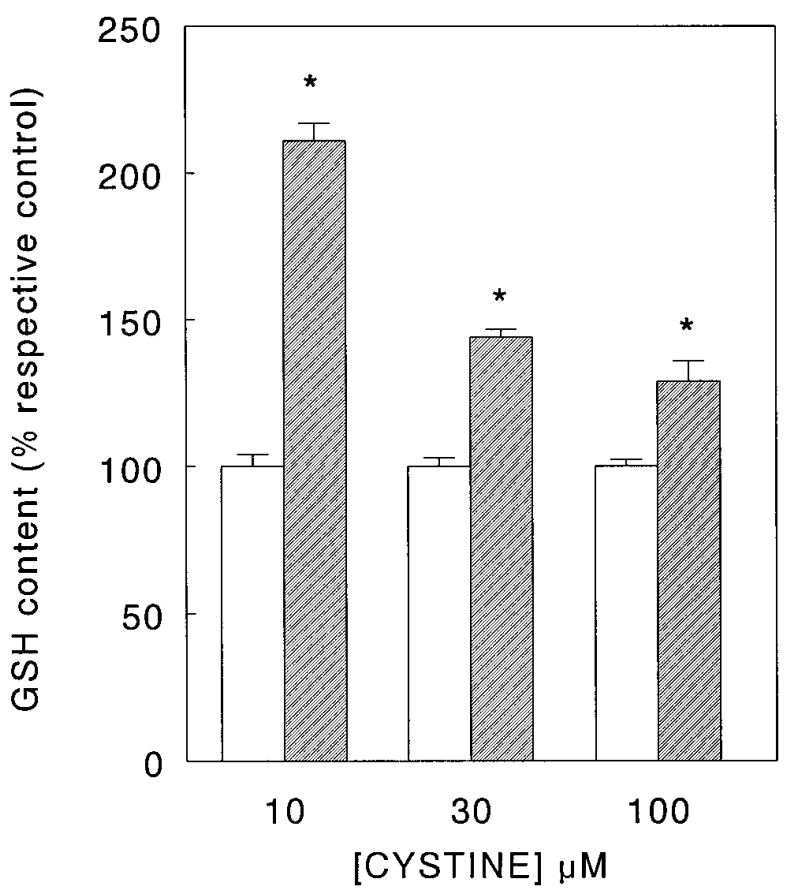

Figure 2. Effect of reserpine on glutathione $(G S H)$ content of PC12 cells in the presence of cystine. PC12 cells, cultured for $2 \mathrm{~d}$, were rinsed free of culture medium and incubated for $3 \mathrm{hr}$ in a phosphate buffer (see Materials and Methods) at $37^{\circ} \mathrm{C}$ with 10,30 , or $100 \mu \mathrm{M}$ cystine in the absence (control) or presence of $50 \mathrm{~nm}$ reserpine, respectively. Subsequently, the cells were lysed and the GSH and protein content in parallel cultures was determined as detailed in Materials and Methods. Data represent the mean \pm SEM $(n=9)$ from three independent experiments. Between experiments, the GSH content after a $3 \mathrm{hr}$ incubation in the absence of reserpine averaged from 0.7 to $2.0 \mathrm{nmol} / \mathrm{mg}$ protein (no cystine), 1.5 to 4.4 $\mathrm{nmol} / \mathrm{mg}$ protein $(10 \mu \mathrm{M}$ cystine $), 4.1$ to $11.1 \mathrm{nmol} / \mathrm{mg}$ protein $(30 \mu \mathrm{M}$ cystine), and 8.7 to $18.3 \mathrm{nmol} / \mathrm{mg}$ protein (100 $\mu \mathrm{M}$ cystine). Therefore, the data are expressed as percentage of respective GSH content at each cystine concentration in the absence of reserpine. ${ }^{*} p<0.005$ versus respective control.

the DA metabolite 3,4-dihydroxyphenylacetic acid (DOPAC) also decreased, albeit to a much smaller extent than those of DA, thus demonstrating ongoing DA breakdown in the absence of granular storage (Table 2). Concomitant with these reserpine-induced effects on DA metabolism, a lasting and statistically significant increase in cellular total GSH content was observed after incubation with the drug for 1,2 , or $3 \mathrm{~d}$ (Table 2). Under these circumstances, however, no effect of reserpine treatment on cell survival was detected, as measured with the MTT assay [0.65 \pm 0.009 vs $0.68 \pm 0.009,0.80 \pm 0.003$ vs $0.77 \pm 0.02,0.93 \pm 0.01$ vs $0.97 \pm 0.02$; mean $\pm \operatorname{SEM}(n=3)$ of absorbance in control versus reserpine treatment group after 1,2 , or $3 \mathrm{~d}$ of incubation with reserpine, respectively].

\section{Effect of $\alpha$ MPT on GSH content}

To rule out the possibility that the reserpine-induced elevation of GSH levels was (partly) attributable to enhanced DA turnover and not to inhibition of granular uptake and/or storage, we incubated the PC12 cells for $24 \mathrm{hr}$ with the tyrosine hydroxlase (TH) inhibitor $\alpha$-methyl- $p$-tyrosine ( $\alpha$ MPT) (Spector et al., 1965) added to the culture medium. Under these conditions, $\alpha$ MPT (0.1-1
$\mathrm{mM}$ ) induced a concentration-dependent lowering of the DA level down to $\sim 15 \%$ of control value (Fig. $3 A$ ), accompanied, however, by a decrease in DOPAC content below the detection limit at all drug concentrations used (data not shown). Concurrently, similar to the results obtained with reserpine, compared with control values total GSH content increased in a concentration-dependent manner in the presence of $\alpha$ MPT (Fig. 3B). After depletion of intracellular DA by treatment for $24 \mathrm{hr}$ with $1 \mathrm{mM} \alpha \mathrm{MPT}$, incubation of the cells for $20 \mathrm{~min}$ in a phosphate buffer (see Materials and Methods) containing DA (0.1-1 mM) again increased the intracellular DA level while simultaneously decreasing GSH level in a concentration-dependent manner (Fig. 4). In contrast, PC12 cells that were not pretreated with $\alpha$ MPT but were incubated for 20 min with DA under similar experimental conditions showed only a marginal increase in intracellular DA content and no change in GSH level (data not shown).

To control for possible "nonspecific," non-DA-related drug effects on cellular GSH metabolism, human D384 glioma cells (Langeveld et al., 1992), not containing any detectable DA, were cultured in DMEM/F-10 containing 10\% FCS and exposed to either reserpine or $\alpha \mathrm{MPT}$ in the concentrations used for the experiments with PC12 cells. Incubation of the cells for up to 24 hr with either of the drugs did not induce any significant changes in cellular GSH content (data not shown). Furthermore, it is important to note that, under none of the above described experimental conditions in PC12 and D384 cells, neither reserpine nor $\alpha \mathrm{MPT}$ affected cell survival as estimated by measurement of protein content (data not shown).

\section{Effect of BSO on DA uptake}

To check whether radiolabeled DA and choline uptake in PC12 cells, cultured under our experimental conditions, was mediated via a high-affinity membrane transport system, the $\mathrm{Na}^{+}$concentration in the incubation buffer was lowered by isomolar replacement of $\mathrm{NaCl}$ by $\mathrm{LiCl}$. Under these conditions, $\left[{ }^{3} \mathrm{H}\right] \mathrm{DA}$ uptake was lowered to $18.2 \pm 0.7 \%$ of the control value [mean \pm SEM $(n=3)$; Student's $t$ test, $p<0.001]$, and $\left[{ }^{14} \mathrm{C}\right]$ choline uptake was lowered to $25 \pm 0.3 \%$ of control [mean $\pm \operatorname{SEM}(n=3)$; Student's $t$ test, $p<0.001$ ]. Moreover, incubation of the cells with either the DA uptake inhibitor GBR $12909(10 \mu \mathrm{M})$ (Andersen, 1989) or the NA uptake inhibitor desmethylimipramine $(10 \mu \mathrm{M})$ (Iversen, 1973) reduced radiolabeled DA uptake down to $0.8 \pm 0.04$ and $1.0 \pm 0.03 \%$ of control, respectively [mean $\pm \operatorname{SEM}(n=3)$; Student's $t$ test, $p<0.001$ ], whereas incubation with the choline uptake inhibitor hemicholinium-3 (1 mM) (Birks and MacIntosh, 1957) reduced choline uptake to $26.6 \pm 0.8 \%$ of control [mean \pm SEM $(n=3)$; Student's $t$ test, $p<0.001]$. Exposure of the PC12 cells for $24 \mathrm{hr}$ to $10 \mu \mathrm{M}$ BSO added to the culture medium, depleted the cellular GSH content down to $15.3 \pm 1.2 \%$ of control [mean $\pm \operatorname{SEM}(n=6)$; Student's $t$ test, $p<0.001]$. Consistent with previous data (Pan and Perez-Polo, 1993), in the presence of this relatively low concentration of BSO no effect was observed on cell survival (measured as protein content in treated and untreated groups), which contrasted with the results obtained after a $24 \mathrm{hr}$ incubation with higher concentrations of the drug, where clear toxicity was induced without an additional effect on GSH levels in the remaining cells (data not shown). After the incubation with BSO $(10 \mu \mathrm{M})$, the high-affinity uptake of $\left[{ }^{3} \mathrm{H}\right] \mathrm{DA}$ was decreased by $\sim 25 \%$, whereas no significant effect on $\left[{ }^{14} \mathrm{C}\right]$ choline uptake occurred (Fig. 5). At the same time, in BSO-treated cultures a slight yet statistically significant lowering of the DA content accompanied by an enhancement of DA turnover was 

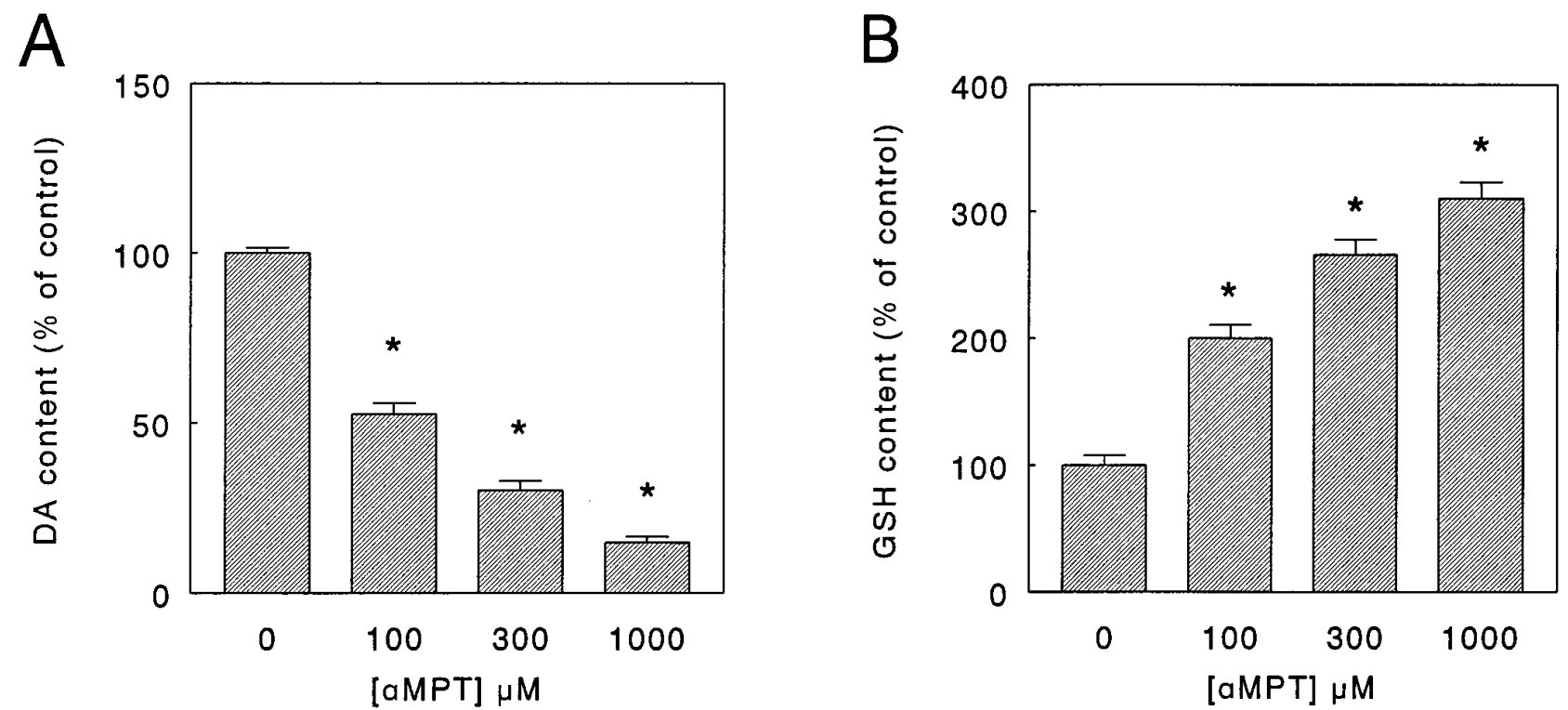

Figure 3. Effect of $\alpha$-methyl-p-tyrosine $(\alpha M P T)$ on dopamine $(D A)$ content $(A)$ and glutathione $(G S H)$ content $(B)$ of PC12 cells. After an initial 24 hr drug-free culture period, without a change of medium (see Materials and Methods), PC12 cells were kept in culture for an additional 24 hr period in the absence $(0 \mu \mathrm{M})$ or presence of 100,300 , or $1000 \mu \mathrm{M} \alpha \mathrm{MPT}$, respectively. Subsequently, the cells were lysed and the DA, GSH, and protein content in parallel cultures was determined as detailed in Materials and Methods. Data represent the mean \pm SEM $(n=5-6)$ from two independent experiments and are expressed as percentage of control (i.e., content after $48 \mathrm{hr}$ of culture in the absence of $\alpha \mathrm{MPT}$ ). Under control conditions, between experiments the DA content averaged from 3.7 to $4.0 \mathrm{nmol} / \mathrm{mg}$ protein, whereas the GSH content averaged from 1.5 to $1.6 \mathrm{nmol} / \mathrm{mg}$ protein, respectively. ${ }^{*} p<0.001$ versus control.

noted [DA content: $94.5 \pm 1.0 \%$ vs control; DOPAC/DA ratio: $108 \pm 1.5 \%$ vs control (mean \pm SEM, $n=6$; Student's $t$ test, $p<0.01)]$.

\section{DISCUSSION}

In general, DA, after its synthesis, is taken up and stored in specialized subcellular organelles, the storage granules, to ensure its regulated release via exocytosis. Most information about the granular transport mechanism(s) and storage mechanism(s) of DA (and monoamines in general) has been obtained by using chromaffin granules isolated from adrenal medullary cells or PC12 cells as experimental substrate (Roda et al., 1980). Thus, it is presently known that the DAergic granular transport system consists of at least two components: (1) a so-called vesicular mono-
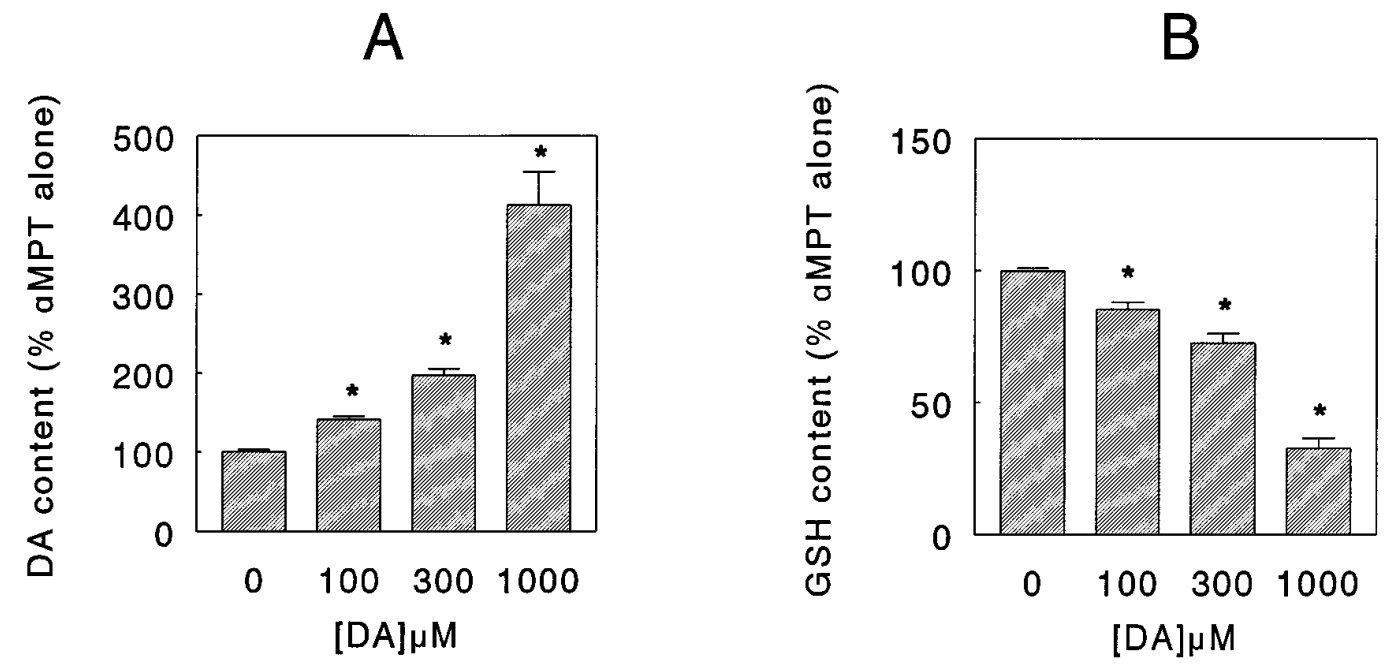

Figure 4. Effect of exogenous dopamine $(D A)$ on the DA content $(A)$ and glutathione $(G S H)$ content $(B)$ of PC12 cells incubated in the presence of $\alpha$-methyl-p-tyrosine $(\alpha M P T)$. After an initial $24 \mathrm{hr}$ drug-free culture period, without a change of medium (see Materials and Methods), PC12 cells were kept in culture for an additional $24 \mathrm{hr}$ period in the absence or presence of $1 \mathrm{mM} \alpha \mathrm{MPT}$. Subsequently, the cells were rinsed free of culture medium and incubated for $20 \mathrm{~min}$ at $37^{\circ} \mathrm{C}$ in a phosphate buffer (see Materials and Methods) in the absence $(0 \mu \mathrm{M})$ or presence of 100,300 , or $1000 \mu \mathrm{M} \mathrm{DA}$, respectively. Thereafter, the cells were lysed and the DA, GSH, and protein content in parallel cultures was determined as detailed in Materials and Methods. Data represent the mean $\pm \operatorname{SEM}(n=6)$ from two independent experiments and are expressed as percentage of DA or GSH content in cells treated only with $\alpha$ MPT. In control cultures (i.e., cells not treated with any drug), the DA content amounted to $5.3 \pm 0.5 \mathrm{nmol} / \mathrm{mg} \mathrm{protein}$, whereas in cultures treated only with $\alpha \mathrm{MPT}$, the DA content amounted to $0.8 \pm 0.1 \mathrm{nmol} / \mathrm{mg}$ protein (mean $\pm \mathrm{SEM}$ ). In control cultures, the GSH content amounted to $2.1 \pm 0.3 \mathrm{nmol} / \mathrm{mg}$ protein, whereas in cultures treated only with $\alpha \mathrm{MPT}$ the GSH content amounted to $4.6 \pm 0.2 \mathrm{nmol} / \mathrm{mg}$ protein (mean $\pm \mathrm{SEM}$ ). ${ }^{*} p<0.001$ versus $\alpha \mathrm{MPT}$ alone (i.e., $0 \mu \mathrm{M}$ DA). 


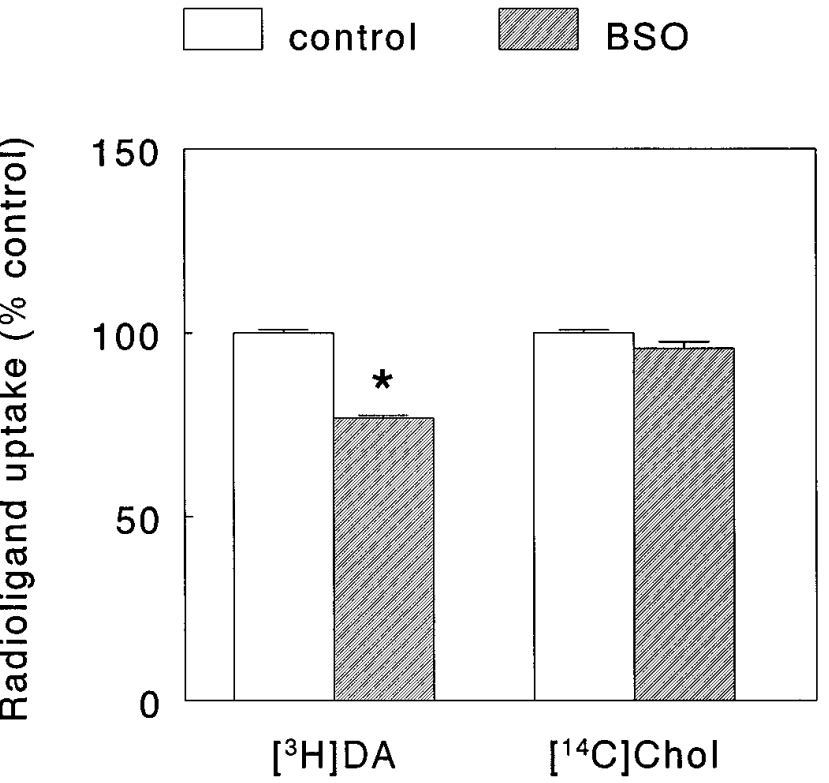

Figure 5. Effect of buthionine sulfoximine (BSO) on the uptake of $\left[{ }^{3} \mathrm{H}\right]$ dopamine $(D A)$ and $\left[{ }^{14} \mathrm{C}\right]$ choline $(\mathrm{Chol})$ in $\mathrm{PC} 12$ cells. After an initial drug-free culture period of $48 \mathrm{hr}$, without a change of medium (see Materials and Methods), PC12 cells were kept in culture for an additional period of $24 \mathrm{hr}$ in the absence (control) or presence of $10 \mu \mathrm{M} \mathrm{BSO}$, respectively. Subsequently, the culture medium was removed and radioligand uptake was determined using a phosphate buffer to which both $\left[{ }^{3} \mathrm{H}\right]$ dopamine and $\left[{ }^{14} \mathrm{C}\right]$ choline had been added, as detailed in Materials and Methods. Data represent the mean $\pm \operatorname{SEM}(n=6)$ from two independent experiments and are expressed as percentage of control (i.e., uptake of either radioligand after $72 \mathrm{hr}$ of culture in the absence of BSO). Under control conditions, the uptake of $\left[{ }^{3} \mathrm{H}\right]$ dopamine and $\left[{ }^{14} \mathrm{C}\right]$ choline amounted to $497,000 \pm 10,900$ and $11,600 \pm 531 \mathrm{dpm}$ (mean \pm SEM), respectively. ${ }^{*} p<0.001$ versus uptake of $\left[{ }^{3} \mathrm{H}\right]$ dopamine under control condition.

amine transporter (VMAT), structurally distinct from the plasma membrane DA transporter, and (2) a vacuolar-type ATP-driven $\mathrm{H}^{+}$pump, which provides the electrochemical gradient on which the transporter depends for its function (Johnson, 1988; Schuldiner, 1994). Drugs such as reserpine and tetrabenazine deplete intracellular DA stores by selectively interfering with transmitter uptake via the VMAT. In the present set of experiments, we used reserpine because it reportedly induces a long-lasting decrease in the DA level of PC12 cells at lower concentrations than tetrabenazine and, moreover, in contrast to tetrabenazine, specifically blocks the transmitter (DA) recognition site on the VMAT (Erickson and Eiden, 1993; Schuldiner et al., 1993).

Our data show that, as reported previously (Greene and Rein, 1977), inhibition of DA transport across the storage granule membrane in PC12 cells by a maximally effective concentration of reserpine (our unpublished observations) induces a fast, almost total, and long-lasting depletion of intracellular DA without affecting cell survival. This demonstrated that, in PC12 cells cultured under our conditions the major part of intracellularly synthesized, endogenous DA is sequestered in the storage granules and does not exert any toxic effect on the cells, as is observed in case of exogenous DA (Michel and Hefti, 1990). Interestingly, the reserpine-mediated emptying of the granular DA stores was accompanied by a substantial and sustained rise in the intracellular total GSH (i.e., reduced GSH + GSSG) content. Using the GSH precursor cystine to stimulate GSH formation, the extent of this reserpine-induced effect appeared to depend on the amount of
GSH being synthesized in the cell and suggested the existence of a (thus far unknown) distinct pool of cytoplasmic GSH intimately linked to the DA storage compartment of PC12 cells. This interpretation of our data is supported moreover by the fact that, irrespective of the amount of GSH present after incubation with increasing doses of cystine, at each cystine concentration the reserpine-mediated rise in GSH content, when calculated as absolute amounts increase, appeared to be very similar. Because it had been reported previously that reserpine affects the cellular GSH status by enhancing DA turnover (Spina and Cohen, 1989), we investigated, in addition, the effect of depletion of DA stores through inhibition of its synthesis. Although blockade of $\mathrm{TH}$ activity effectively lowered intracellular DA levels and, in contrast to reserpine, also reduced DA breakdown, again a significant increase in GSH content was detected that was of comparable magnitude to that observed with reserpine. Because inhibition of GSH formation did not prevent the observed effect, we concluded that the increased GSH level in the presence of reserpine was not attributable to enhanced synthesis but may be caused by a reduction in the use of GSH for cell function as a result of the emptying of the granular DA stores. This conclusion is supported moreover by our data showing that, after an increase of GSH content caused by depletion of stored DA with $\alpha \mathrm{MPT}$, direct refilling of the DA stores by incubation with exogenous DA immediately reduced the GSH level of the cells back to control values (i.e., GSH content of cells not treated with $\alpha$ MPT).

Although the described experiments demonstrated a relationship between the granular storage of DA and cellular GSH homeostasis, additional data were needed to establish whether GSH itself plays a role in the granular transport of DA. In central and peripheral neurons, released DA is recovered from the synapse via translocation into the cytoplasm by a $\mathrm{Na}^{+}$-dependent membrane transporter (Rudnick and Clark, 1993). Subsequently, the DA taken up is protected from metabolic breakdown by storage in so-called presynaptic vesicles by the above described mechanism. Adrenal medulla-derived cells such as the PC12 cell line are known to preferentially accumulate (radiolabeled) DA from the external medium in the chromaffin granules in a way similar to that of DAergic neurons (Greene and Rein, 1977; Rudnick and Clark, 1993). Our results show that depletion of GSH, by inhibition of its synthesis with the $\gamma$-glutamylcysteine synthetase inhibitor BSO (Meister, 1991), significantly reduces the $\mathrm{Na}^{+}$-dependent cellular uptake of radiolabeled DA in PC12 cells. In addition to DA (and NA), PC12 cells are known to transport (radiolabeled) choline, the precursor of ACh, across the plasma membrane using a transporter molecule (Melega and Howard, 1981). In our experiments, depletion of GSH had no effect on the uptake of radiolabeled choline. Thus, although our experimental setup does not allow us to differentiate between the transport of DA across the plasma membrane or the chromaffin granule membrane, in our opinion, by inference, it is more likely that the diminished uptake of DA reflects a lesion in the chromaffin granule membrane transport system rather than in its plasma membrane counterpart. Contrary to expectation, however, the supposed defect in DA storage led only to a small, although statistically significant, rise in the indices of DA metabolism, i.e., a decrease in the steady-state level of endogenous DA in combination with an increase in DA turnover. Although further investigation of this issue is needed, the apparent contradiction may be explained by the fact that, under our experimental conditions, the depletion of GSH over a $24 \mathrm{hr}$ time period caused only a relatively 
small decrease in DA accumulation of which the effect on endogenous DA metabolism is still unknown.

Interestingly, the above described data are very similar to those obtained previously by Elroy-Stein and Groner (1988), who found a $50-80 \%$ reduction in the uptake of monoamines, including DA, but no change in the uptake of choline in transformed PC12 cells overexpressing the human $\mathrm{Cu} / \mathrm{Zn}$-superoxide dismutase gene. Using elegant techniques, they demonstrated that the impaired monoamine accumulation was caused by a diminished electrochemical gradient across the chromaffin granule membrane in the transformed clones. As mentioned already, the electrochemical gradient is the driving force for the transport of monoamines, such as DA, into the storage granules and is generated by a vacuolartype, ATP-dependent $\mathrm{H}^{+}$pump. This subclass of proton pumps, including the one present in the chromaffin granule membrane, is known to be extremely sensitive to sulfhydryl modification by oxidants such as $\mathrm{H}_{2} \mathrm{O}_{2}$ (Rudnick, 1986), against which it is protected by reductants like GSH (Dschida and Bowman, 1995). Thus, malfunction of the pump may be attributable either to increased production of ROS, such as occurs in cells with a high superoxide dismutase activity (Elroy-Stein and Groner, 1988; Schickler et al., 1989), or to decreased protection, for instance, after reduction of cellular GSH levels. Moreover, it is conceivable that oxidative damage to the proton pump also forms the basis of our previous observations demonstrating a preferential inhibition of the vesicular storage of DA in the nigro-striatal system of the rat brain by $\mathrm{H}_{2} \mathrm{O}_{2}$ (Langeveld et al., 1995). At present, experiments along the lines described by Elroy-Stein and Groner (1988) are being implemented in our laboratory to identify, possibly, a proton pump deficit as the cause of the diminished uptake of DA in GSH depleted PC12 cells.

In conclusion, our data, taken together, strongly suggest that GSH is involved in the uptake of DA in the chromaffin granules of PC12 cells. Although further research is clearly warranted and alternative explanations are available, considering the fact that DA is easily oxidized (Bindoli et al., 1992), it is tempting to propose a mechanism in which GSH is used to protect susceptible parts of the transport system against the potentially toxic interaction with DA oxidation products during DA uptake. Apparently, during this process GSH is transformed into a compound, for instance, a glutathionyl conjugate (Nappi and Vass, 1994), which escapes detection by our enzyme recycling method, which is rather specific for GSH and GSSG (Redegeld et al., 1988). Thus, a reduction in granular storage of DA, in our experiments induced by reserpine or $\alpha \mathrm{MPT}$, may lead to an increase in measurable GSH content. Conversely, a lowering of GSH content will leave the granular DA transport system relatively unprotected against oxidative damage, resulting in a diminished storage of the transmitter.

Notwithstanding the fact that differences in molecular structure and function of VMATs have been noted (Peter et al., 1994) and that, in general, data obtained in adrenal medulla-derived PC12 cells are not directly extrapolatable to DAergic neurons, concentration of DA in synaptic vesicles of neurons is thought to involve similar mechanisms as those active in chromaffin granules (Schuldiner, 1994). GSH is present in neurons (Pileblad et al., 1991), and in PD loss of GSH has been implicated as an early event in the pathogenesis of the disorder (Dexter et al., 1994). Looking at our results, it seems plausible to suggest that the consequent shift in the neuronal redox balance will initiate the self-sustaining cycle already described in the introductory remarks, in which a dysfunction in vesicular storage of DA, probably at the level of the proton pump, eventually leads to nigro-striatal cell death through massive oxidative stress. In this context, it is of interest to note that oxidative degeneration of DAergic neurons indeed has been observed after interference with the vesicular electrochemical gradient (Cubells et al., 1994).

\section{REFERENCES}

Adams JD, Odunze IN (1991) Oxygen free radicals and Parkinson's disease. Free Radic Biol Med 10:161-169.

Andersen PH (1989) The dopamine uptake inhibitor GBR 12909: selectivity and molecular mechanism of action. Eur J Pharmacol 166:493-504.

Baker MA, Cerniglia GJ, Zaman A (1990) Microtiter plate assay for the measurement of glutathione and glutathione disulfide in large numbers of biological samples. Anal Biochem 190:360-365.

Birks RI, MacIntosh FC (1957) Acetylcholine metabolism at nerveendings. Br Med Bull 13:157-161.

Bindoli A, Rigobello MP, Deeble DJ (1992) Biochemical and toxicological properties of the oxidation products of catecholamines. Free Radic Biol Med 13:391-405.

Bradford M (1976) A rapid and sensitive method for the quantification of microgram quantities of protein utilizing the principle of protein-dye binding. Anal Biochem 72:248-254.

Carlsson A (1965) Drugs which block the storage of 5-hydroxytryptamine and related amines. Handb Exp Pharmacol 19:529-592.

Cubells JF, Rayport S, Rajendran G, Sulzer D (1994) Metamphetamine neurotoxicity involves vacuolation of endocytic organelles and dopamine-dependent intracellular oxidative stress. J Neurosci 14:2260-2271.

Dexter DT, Sian J, Rose S, Hindmarsh JG, Mann VM, Cooper JM, Wells FR, Daniel SE, Lees AJ, Schapira AHV, Jenner P, Marsden CD (1994) Indices of oxidative stress and mitochondrial function in individuals with incidental Lewy body disease. Ann Neurol 35:38-44.

DiMonte DA, Chan P, Sandy MS (1992) Glutathione in Parkinson's disease: a link between oxidative stress and mitochondrial damage? Ann Neurol 32:S111-S115.

Dschida WJA, Bowman BJ (1995) The vacuolar ATPase: sulfite stabilization and the mechanism of nitrate inactivation. J Biol Chem 270:1557-1563.

Elroy-Stein O, Groner Y (1988) Impaired neurotransmitter uptake in PC12 cells overexpressing human $\mathrm{Cu} / \mathrm{Zn}$-superoxide dismutase: implication for gene dosage effects in Down's syndrome. Cell 52:259-267.

Erickson JD, Eiden LE (1993) Functional identification and molecular cloning of a human brain vesicle monoamine transporter. J Neurochem 61:2314-2317.

Gibb WRG, Lees AJ (1991) Anatomy, pigmentation, ventral and dorsal subpopulations of the substantia nigra, and differential cell death in Parkinson's disease. J Neurol Neurosurg Psych 54:388-396.

Greene LA, Rein G (1977) Release, storage and uptake of catecholamines by a clonal cell line of nerve growth factor (NGF) responsive pheochromocytoma cells. Brain Res 129:247-263.

Greene LA, Tischler AS (1976) Establishment of a noradrenergic clonal line of rat adrenal pheochromocytoma cells which respond to nerve growth factor. Proc Natl Acad Sci USA 73:2424-2428.

Hirsch EC, Brandel JP, Galle P, Javoy-Agid F (1991) Iron and aluminum increase in the substantia nigra of patients with Parkinson's disease: an X-ray microanalysis. J Neurochem 56:446-451.

Iversen LL (1973) Catecholamine uptake processes. $\mathrm{Br}$ Med Bull 29:130-135.

Jenner P (1993) Altered mitochondrial function, iron metabolism and glutathione levels in Parkinson's disease. Acta Neurol Scand 87[Suppl 146]:6-13.

Johnson Jr RG (1988) Accumulation of biological amines into chromaffin granules: a model for hormone and neurotransmitter transport. Physiol Rev 68:233-307.

Langeveld CH, Van Waas MP, Stoof JC, Sutanto W, De Kloet ER, Wolbers JG, Heimans JJ (1992) Implication of glucocorticoid receptors in the stimulation of human glioma cell proliferation by dexamethasone. J Neurosci Res 31:524-531.

Langeveld CH, Schepens E, Stoof JC, Bast A, Drukarch B (1995) Differential sensitivity to hydrogen peroxide of dopaminergic and noradrenergic neurotransmission in rat brain slices. Free Radic Biol Med 19:209-217. 
Maker HS, Weiss C, Silides DJ, Cohen G (1981) Coupling of dopamine oxidation (monoamine oxidase activity) to glutathione oxidation via the generation of hydrogen peroxide in rat brain homogenates. J Neurochem 36:589-593.

Meister A (1991) Glutathione deficiency produced by inhibition of its synthesis, and its reversal: applications in research and therapy. Pharmacol Ther 51:155-194.

Meister A, Andersson ME (1983) Glutathione. Annu Rev Biochem 52:711-760.

Melega WP, Howard BD (1981) Choline and acetylcholine metabolism in PC12 secretory cells. Biochemistry 20:4477-4483.

Michel PP, Hefti F (1990) Toxicity of 6-hydroxydopamine and dopamine for dopaminergic neurons in culture. J Neurosci Res 26:428-435.

Nappi AJ, Vass E (1994) The effects of glutathione and ascorbic acid on the oxidations of 6-hydroxydopa and 6-hydroxydopamine. Biochim Biophys Acta 1201:498-504.

Olanow CW (1992) An introduction to the free radical hypothesis in Parkinson's disease. Ann Neurol 32:S2-S9.

Pan Z, Perez-Polo JR (1993) Role of nerve growth factor in oxidant homeostasis: glutathione metabolism. J Neurochem 61:1713-1721.

Peter D, Jimenez J, Liu Y, Kim J, Edwards RH (1994) The chromaffin granule and synaptic vesicle amine transporters differ in substrate recognition and sensitivity to inhibitors. J Biol Chem 269:7231-7237.

Pileblad E, Eriksson PS, Hansson E (1991) The presence of glutathione in primary neuronal and astroglial cultures from rat cerebral cortex and brain stem. J Neural Transm 86:43-49.

Redegeld FA, Van Opstal MA, Houdkamp E, Van Bennekom WP (1988) Determination of glutathione in biological material by flow-injection analysis using an enzymatic recycling reaction. Anal Biochem 174:489-495.

Riederer P, Sofic E, Rausch W-D, Schmidt B, Reynolds GP, Jellinger K, Youdim MBH (1989) Transition metals, ferritin, glutathione, and ascorbic acid in Parkinsonian brains. J Neurochem 52:515-520.

Roda LG, Nolan JA, Seung UK, Hogue-Angeletti RA (1980) Isolation and characterization of chromaffin granules from a pheochromocytoma (PC 12) cell line. Exp Cell Res 128:103-109.

Rudnick G (1986) ATP-driven $\mathrm{H}^{+}$pumping into intracellular organelles. Annu Rev Physiol 48:403-413.

Rudnick G, Clark J (1993) From synapse to vesicle: the reuptake and storage of biogenic amine neurotransmitters. Biochim Biophys Acta 1144:249-263.

Sampath D, Jackson GR, Werrbach-Perez K, Perez-Polo JR (1994) Effects of nerve growth factor on glutathione peroxidase and catalase in PC12 cells. J Neurochem 62:2476-2479.

Schickler M, Knobler H, Avraham KB, Elroy-Stein O, Groner Y (1989) Diminished serotonin uptake in platelets of transgenic mice with increased $\mathrm{Cu} / \mathrm{Zn}$-superoxide dismutase activity. EMBO J 8:1385-1392.

Schuldiner S (1994) A molecular glimpse of vesicular monoamine transporters. J Neurochem 62:2067-2078.

Schuldiner S, Liu Y, Edwards RH (1993) Reserpine binding to a vesicular amine transporter expressed in Chinese hamster ovary fibroblasts. J Biol Chem 268:29-34.

Sofic E, Lange KW, Jellinger K, Riederer P (1992) Reduced and oxidized glutathione in the substantia nigra of patients with Parkinson's disease. Neurosci Lett 142:128-130.

Spector S, Sjoerdsma A, Udenfriend S (1965) Blockade of endogenous norepinephrine synthesis by alpha-methyl-tyrosine, an inhibitor of tyrosine hydroxylase. J Pharmacol Exp Ther 147:86-95.

Spina MB, Cohen G (1988) Exposure of school synaptosomes to L-dopa increases levels of oxidized glutathione. J Pharmacol Exp Ther 247:502-507.

Spina MB, Cohen G (1989) Dopamine turnover and glutathione oxidation: implications for Parkinson's disease. Proc Natl Acad Sci USA 86:1398-1400.

Tietze F (1969) Enzymatic method for quantification of total and oxidized glutathione: applications to mammalian blood and other tissue. Anal Biochem 27:502-522.

Van Muiswinkel FL, Jongenelen CAM, Schepens HTWJ, Stoof JC, Drukarch B (1995) Effects of chronic activation of dopamine D-2 receptors in cultures of rat fetal dopaminergic neurons: indications for alterations in functional activity. Dev Brain Res 85:128-136.

Westerink BHC, Mulder TBA (1981) Determination of picomole amounts of dopamine, noradrenaline, 3,4-dihydroxyphenylalanine, 3,4-dihydroxyphenylacetic acid, homovanillic acid, and 5hydroxyindoleacetic acid in nervous tissue after one-step purification on Sephadex G-10, using high-performance liquid chromatography with a novel type of electrochemical detection. J Neurochem 36:1449-1462. 